\title{
Middle pregnancy ultrasound screening for fetal chromosomal diseases
}

\author{
LI LIU ${ }^{1}$, PING ZHOU ${ }^{1}$, ZEMIN CAO ${ }^{1}$ and XIAOJUN TAN ${ }^{2}$ \\ ${ }^{1}$ Department of Ultrasonic Medicine, The Third Xiangya Hospital of Central South University, Changsha, Hunan 410013; \\ ${ }^{2}$ Department of Genetic and Reproductive Science, The Xiangtan Central Hospital, Xiangtan, Hunan 411413, P.R. China
}

Received July 26, 2016; Accepted July 20, 2017

DOI: $10.3892 / \mathrm{mmr} .2017 .7548$

\begin{abstract}
Prenatal examinations, including serological screening and ultrasound screening, are the methods determining a risk of fetal chromosomal disease. The current study is aimed to assess whether ultrasound screening can effectively assist the screening for fetal chromosomal disease among pregnant women with a single abnormal serum marker. Following serologic screening, pregnant women at 18-32 weeks underwent systematic fetal ultrasound analysis. In this study, 99 pregnant women with an abnormal serum marker and fetal ultrasound abnormalities underwent prenatal diagnosis of amniotic fluid or umbilical cord blood, with confirmation by pathological examination performed following birth or induced labor. A total of 95 cases with an abnormal serum marker but no fetal ultrasound abnormalities were used as the control group, and underwent prenatal karyotype analysis. The rate of fetal chromosomal abnormalities of women with ultrasound abnormalities was significantly higher than in the control group. The fetal chromosomal abnormalities rate in pregnant women with a history of abnormal gestation/birth was higher than in pregnant women with a normal history. The present results suggest that ultrasound examination can facilitate screening for fetal chromosome abnormalities in pregnant women with a single abnormal serum marker.
\end{abstract}

\section{Introduction}

Chromosome diseases are usually caused by a change in chromosome number and structural abnormalities. Chromosome number abnormalities include autosomal and sex chromosome abnormalities (1). Autosomal abnormalities include aneuploidy

Correspondence to: Professor Ping Zhou, Department of Ultrasonic Medicine, The Third Xiangya Hospital of Central South University, 138 Tongzi Road, Changsha, Hunan 410013, P.R. China E-mail: fengnjdhw@sina.com

Key words: chromosomal abnormalities, prenatal ultrasound screening, serologic trigeminy screening, single abnormal serum markers abnormalities, such as trisomy 21, trisomy 18 and trisomy 13 , chimera, such as $46, \mathrm{XX} / 47, \mathrm{XX}$ and +21 , and polyploid abnormalities, such as single triploid and tetraploid chimera. Sex chromosome abnormalities include Turner's syndrome and sex chromosome triploid abnormalities. Chromosome structure abnormalities include chromosome deletion, translocation, inversion, circular chromosome and isochromosome (2). Chromosome aberration can occur during the process of germ cell meiosis and the development of the fertilized egg cells, or in human cells. Chromosome abnormalities account for $50-60 \%$ of spontaneous miscarriages, and occur in $0.5-0.73 \%$ of newborns $(3,4)$. Chromosome abnormalities usually result in developmental arrest and spontaneous miscarriage. The first confirmed human chromosome number abnormality, trisomy 21 , also known as Down's syndrome $(5,6)$, it is one of the most common chromosomal abnormalities (occurs in $\sim 1.5 \%$ of newborns). Its clinical features include a characteristic face, mental retardation, multiple malformations and derma to glyph changes (5).

Due to of environmental pollution and hereditary factors, the rates of birth defects including neural tube defects, congenital heart disease and Down's syndrome are high (7), Down's syndrome has been reported to occur at a rate of approximately 1.28 in every 1,000 live births in China (8), The etiology of birth defects is complex, including chromosome abnormalities, single genetic defects, polygenic inheritance and teratogens, but chromosome abnormalities account for $\sim 6 \%$ of birth defects (9). Currently, there is no effective method for preventing and treating chromosome diseases.

Prenatal examinations are performed to screen for and diagnose chromosomal abnormalities. Screening involves serological and ultrasound screening (10). Chorionic villus biopsy (11), amniocentesis, fetal umbilical cord blood puncture and biopsy, and fetal endoscopy are used for the diagnosis of chromosomal abnormalities (11-14). Fetal karyotype analysis is the gold standard for prenatal diagnosis. In developed countries, antenatal examination is common even in the first trimester (15), but in developing country, the majority of pregnant women register for obstetric examination in the second trimester. Additionally, invasive prenatal diagnosis can cause miscarriage, and the rate can reach $1 \%$ (7). Currently, prenatal diagnosis methods are commonly performed for pregnant women identified as high-risk in the prenatal screening (16). 
Therefore, developing safe, effective and economical prenatal screening methods is of important clinical significance.

Second trimester maternal serologic trigeminy screening of $\alpha$-fetoprotein (AFP), free $\beta$-human chorionic gonadotropin (HCG) and unconjugated-estriol (uE3) at 15-20 weeks is a popular method (17). Pregnant women with a risk rate of Down's syndrome $<1 / 270$ and trisomy 18 risk rate $<1 / 350$, but with abnormal serum markers [AFP Multiples of the Median $(\mathrm{MoM}) \geq 2.5$; AFP MoM <0.7; HCG MoM > 2.5; HCG MoM $<0.25$; or $\mathrm{UE} 3 \mathrm{MoM}<0.7)$ were involved in the present study. The aim of the current study was to screen out the chromosome abnormalities of these pregnant women. Systematic fetal sonography was performed at the Third Xiangya Hospital of Central South University (Changsha, China) and Xiangtan Center Hospital (Xiangtan, China). If ultrasound abnormalities were observed, amniotic cavity puncture or umbilical cord blood tube centesis were performed, combined with chromosome karyotype analysis. In this process ultrasound screening was useful for effectively screening for chromosome abnormalities. Furthermore, preliminary analysis was performed on the association between different pregnancy histories and the risk of chromosomal abnormalities, and the association between the detection of abnormal features on the fetal ultrasound and the detection of chromosomal abnormalities, which may provide a more effective method to screen for fetal chromosomal diseases.

\section{Materials and methods}

Subjects. Between June, 2013 and April, 2015, 8,469 pregnant women were recruited to this study $(3,456$ from Xiangtan Center Hospital and 5,014 from The Third Xiangya Hospital of Central South University, Hunan, China), aged 20-35. At 16-28 weeks' gestation, second trimester serologic trigeminy screening was performed; 1,217 cases with a Down's syndrome risk rate $<1 / 270$ and 18 -trisomy risk rate $<1 / 350$, exhibited single abnormal serum markers (AFP MOM $\geq 2.5$, AFP MOM $<0.7$, HCG MOM $>2.5$, HCG MOM $<0.25$ or uE3 MOM <0.7). Of the patients with a single abnormal serum marker, 1,012 were primipara, and 205 were multipara. Systematic fetal ultrasound was performed at 18-32 weeks' gestation. In the group with abnormal markers, fetal ultrasound abnormalities were observed in 99 women, therefore, prenatal diagnosis was performed using amniotic fluid or umbilical cord blood. Abnormalities were confirmed by pathological examination following birth or induced labor. Pregnant women with abnormal markers but without fetal ultrasound abnormalities (1,118 in total) were used as the control, 95 underwent prenatal diagnosis. All study methods were approved by the Ethics Committee of the Third Xiangya Hospital of Central South University and Xiangtan Center hospital. All subjects provided written formal consent.

Ultrasonography. At 18-32 weeks, pregnant women were examined by systematic ultrasound examination (abdominal probe 3.5-6 MHz) with attention paid to the fetal head, face, spine, internal organs, limbs, placenta, amniotic fluid, umbilical cord, the measurement of biparietal diameter, head circumference, cerebellar diameter, vertical pool depth, abdominal perimeter, femur and humerus. If an abnormality was identified, detailed inspection was performed on other areas or organs. If a surface deformity, such as facial or foot deformity was identified, three-dimensional ultrasound imaging was performed to provide more intuitive, visual and accurate information.

Ultrasound examination assessment standard. Prenatal ultrasound screening for fetal chromosomal disease aimed to screen for two types of abnormality: i) Anatomical malformations of the fetus, such as cleft lip palate and cardiac abnormalities; and ii) Markers of chromosomal abnormalities, such as neck soft tissue layer thickening and lateral ventricle mild expansion. These indicators are also termed soft marker ultrasound anomalies.

Amniotic fluid cells chromosome analysis. Amniotic fluid (20 ml) was women at 18-24 weeks by amniotic cavity puncture under ultrasound guidance, then was transferred into two $15 \mathrm{ml}$ sterile centrifuge tubes. Centrifugation was performed at $800 \mathrm{x} \mathrm{g}$ and $25^{\circ} \mathrm{C}$ for $10 \mathrm{~min}$, the supernatant was discarded and the remainder $(0.5-1 \mathrm{ml})$ was used to prepare a single-cell suspension. The cells were transferred to a culture bottle with $3 \mathrm{ml} \mathrm{F10} \mathrm{media} \mathrm{(pH} \mathrm{6.8)} \mathrm{and} 1 \mathrm{ml}$ fetal bovine serum (25\%) (both Sigma-Aldrich; Merck KGaA, Darmstadt, Germany) added. Cells were maintained at $37^{\circ} \mathrm{C}$ in a $5 \% \mathrm{CO}_{2}$ incubator. Fiber or epithelioid cell growth was observed within 5-6 days in culture, and cells entered a vigorous growth period in 8-14 days. When 4-6 colonies formed in each bottle, the culture medium was refreshed, and culture was continued for 2 days. Under a light microscope (magnification, x30-40), $3-5$ round cells were observed in each view, then thymidine $(0.3 \mathrm{mg} / \mathrm{ml})$ was added. Following treatment for $14-18 \mathrm{~h}$, cells were washed twice with F10 medium, and then $2.5 \mathrm{ml} \mathrm{F} 10$ and $1.5 \mathrm{ml}$ calf serum (25\%) (Sigma-Aldrich; Merck KGaA), and cultured at $37^{\circ} \mathrm{C}$ for $\sim 10 \mathrm{~h}$. When numerous round large cells were observed, actinomycin D $(2 \mu \mathrm{g} / \mathrm{ml})$ or ethidium bromide $(10 \mu \mathrm{g} / \mathrm{ml})$ were added and cells were incubated with colchicine $(0.2-0.3 \mu \mathrm{g} / \mathrm{ml})$ for $1.5 \mathrm{~h}$ before the cells were harvested. Adherent cells were removed with a bamboo peeling tool and the cell suspension was transferred to a $10 \mathrm{ml}$ centrifuge tube and centrifuged at $2,000 \mathrm{x}$ for $10 \mathrm{~min}$ and at $25^{\circ} \mathrm{C}$. The supernatant was discarded and cells were resuspended in a $3 \mathrm{ml}$ mixture of $0.4 \%$ potassium chloride and $0.4 \%$ sodium citrate $(1: 1)$ and incubated in a water bath for 4-6 min at $37^{\circ} \mathrm{C}$. Cells were fixed in a mixture of methanol and glacial acetic acid $(3: 1 ; 0.5 \mathrm{ml})$ and centrifuged for $8 \mathrm{~min}$ at $2,500 \mathrm{x} \mathrm{g}$ and $25^{\circ} \mathrm{C}$. The supernatant was discarded and fixed with the new fixative for $>30 \mathrm{~min}$ in two changes. After using ice to cool slides, small droplets of the cell suspension were placed onto slides and passed through a flame two to three times, then heated to $75^{\circ} \mathrm{C}$ for $2-3 \mathrm{~h}$ and naturally cooled to $\sim 37^{\circ} \mathrm{C}$.

Umbilical cord blood cell chromosome analysis. Cord blood centesis was performed at 24-32 weeks gestation, except onesubject whose fetal amniotic fluid chromosome analysis result (detected by both amniotic fluid and cord blood) was trisomy 21 syndrome; her cord blood was retained for further consultation before induced labor. Following the addition of heparin $(0.5 \mathrm{U} / \mathrm{ml})$ anticoagulant, cord blood was cultured for $72 \mathrm{~h}$ in RPMI-1640 medium (Sigma-Aldrich; Merck KGaA) 
containing 25\% calf serum (Sigma-Aldrich; Merck KGaA). Thymine nucleoside $(0.3 \mathrm{mg} / \mathrm{ml})$ was added and incubated at $37^{\circ} \mathrm{C}$ for $17 \mathrm{~h}$ then washed with RPMI-1640 twice to remove excess thymine. RPMI-1640 medium $(5 \mathrm{ml})$ and bromodeoxyuridine $(12 \mu \mathrm{g} / \mathrm{ml})$ was added and incubated at $37^{\circ} \mathrm{C}$ for $5 \mathrm{~h}$. Actinomycin D $(6 \mathrm{mg} / \mathrm{ml})$ was added and cultured for $60 \mathrm{~min}$. Finally, colchicine $(0.4 \mu \mathrm{g} / \mathrm{ml})$ was added and after $10 \mathrm{~min}$ the cells were transferred into a $10 \mathrm{ml}$ centrifuge tube and centrifuged at 1,600-2,000 $\mathrm{x}$ g for $10 \mathrm{~min}$ at room temperature and the supernatant was removed. Preheated $\left(37^{\circ} \mathrm{C}\right) 0.4 \%$ potassium chloride and $0.4 \%$ sodium citrate $(1: 1 ; 8 \mathrm{ml})$ was added and incubated at $37^{\circ} \mathrm{C}$ for $15 \mathrm{~min}$. The fixative of methanol and glacial acetic acid $(3: 1 ; 1 \mathrm{ml})$ was added, gently mixed, and centrifuged at 2,400 $\mathrm{xg}$ for $10 \mathrm{~min}$ at room temperature. The supernatant was removed, and $8 \mathrm{ml}$ of the fixative was added; fixative was changed every $30 \mathrm{~min}$ at least twice, with 2,400 x g centrifugation for $10 \mathrm{~min}$ performed between fixations. The upper layer of fixative was removed and 8-10 drops of new fixative was added. The cell aggregates were combined into a single cell suspension. Slides were precooled and 1-2 drops of the cell suspension were added to slides, which were then immediately passed through a flame, then heated to $75^{\circ} \mathrm{C}$ for $2-3 \mathrm{~h}$ and allowed to cool to $37^{\circ} \mathrm{C}$.

$G$ banding. The sample slides were incubated for 2-3 $\mathrm{h}$ at $37^{\circ} \mathrm{C}$ then $0.025 \%$ preheated trypsin was added for $30-75 \mathrm{sec}$. Slides were rinsed in phosphate buffer solution $(\mathrm{pH}$ 6.8) for $\sim 15 \mathrm{sec}$. Slides were dyed with Giemsa dye solution (1:10) for 30-40 min, washed for a few seconds with tap water and air-dried.

Microscopy. Middle division phase cells were observed using a light microscope and a certain number cells ( $\sim 50$ cells) with a distinct chromosome spread were chosen, and the chromosome number was calculated to determine the diploid chromosome number. Three mitosis phases were observed under an oil immersion lens to determine whether the chromosome zone was normal.

Statistical analysis. SPSS statistics software version 12.0 (SPSS, Inc., Chicago, IL, USA) is used for statistical analysis; $\chi^{2}$ analysis was used to comparatively analyze the rate of fetal chromosomal abnormalities between the observed group and the control group. Comparisons among groups were performed by $\chi^{2}$ and $t$ test. Data are expressed as the mean \pm standard error. $\mathrm{P}<0.05$ was considered to indicate a statistically significant difference.

\section{Results}

Ultrasound screening results. Ultrasounds revealed that 99 of 1,217 pregnant women with single abnormal serum markers had prenatal abnormalities, all of which were confirmed by pathological examination of the fetus. Only certain minor deformities were missed by ultrasound diagnosis, such as malformation of the urinary or reproductive tract, and finger/toe malformation.

Cytogenetic results from umbilical cord blood and amniotic fluid specimens. Amniotic fluid cell culture is the safer method of prenatal diagnosis at 18-24 weeks compared with umbilical cord blood analysis. The amniotic fluid is $>200 \mathrm{ml}$ and easy to replenish, and the cells are abundant and easy to culture. However, in long term culture, the amniotic fluid cells are vulnerable to contamination, therefore a strictly sterile culture must be observed.

Of the 99 pregnant women with abnormalities revealed by ultrasound, the culture of two amniotic fluid specimens failed, and 97 cases underwent chromosome karyotype analysis. One of the 97 women had a history of two problematic pregnancies, 37 cases had had one problematic pregnancy; none had a history of trisomy 21 . Of the 38 cases with abnormal gestation and parturition history, seven fetal chromosomal abnormalities were identified in this study: Two trisomy 18 , one trisomy 21 , three trisomy 13 and one 45, X (Turner syndrome). Two fetal chromosomal abnormalities were identified in the 59 women without abnormal gestation and parturition history: One trisomy 18 and one trisomy 21.

Samples were taken from 95 pregnant women with abnormal serum markers but no fetal ultrasound abnormalities as the control group. One umbilical cord blood specimen became contaminated and the culture of two amniotic fluid specimens failed. Complete karyotype analysis was performed on 92 controls $(96.8 \%$; 88 cases using amniotic fluid cell, 7 cases using cord blood cell) with no chromosomal abnormalities identified.

In patients with abnormal serum markers and ultrasound abnormalities, chromosome analysis was performed successfully for 97 cases (Table I); 57 had single abnormalities on the ultrasound and 40 had multiple abnormalities. Of those with a single abnormality, 2 cases of chromosomal abnormalities were identified, and of those with multiple abnormalities, 9 chromosome abnormalities were identified (Table II). In the group with abnormalities observed on the ultrasound, 88 cases had a normal chromosome karyotype (90.7\%) and nine cases had abnormal karyotype $(9.28 \%)$; two cases with trisomy 21 $(2.06 \%)$, three cases with trisomy $18(3.09 \%)$, three cases with trisomy $13(3.09 \%)$ and one case with 45,X (Turner syndrome; $1.03 \%)$. Ultrasound images of 5 cases with ultrasound and chromosomal abnormalities (Figs. 1-5). Of the 9 cases with chromosomal abnormalities, 5 of the pregnant womenwereaged $>30$ years old (55.6\%). Representative normal and abnormal chromosome karyotype maps are presented in Fig. 6.

Comparison of chromosome abnormality rate in different groups. Comparison of fetal chromosomal abnormality rate between the control group and those with abnormalities identified by ultrasound is presented in Table III and Fig. 7A. The rate of fetal chromosomal abnormalities of in cases with abnormalities identified by ultrasound is significantly higher than that of the control group $(\mathrm{P}<0.01)$. Comparison of the fetal chromosomal abnormality rate of the 97 cases with abnormalities identified by ultrasound with different gestation and birth histories is presented in Table IV and Fig. 7B. In cases with abnormalities identified by ultrasound, there were 38 pregnant women with abnormal gestation and birth history, including previous fetal abnormalities, stillbirth and habitual miscarriage, [seven chromosomal abnormalities (18.4\%), they were two trisomy 18 , one trisomy 21 , three trisomy 13 and one 
Table I. Chromosomal abnormalities of 97 cases with abnormalities identified by ultrasound.

\begin{tabular}{|c|c|c|c|}
\hline Group & $\begin{array}{l}\text { Number of } \\
\text { cases }\end{array}$ & $\begin{array}{c}\text { Number of } \\
\text { chromosomal } \\
\text { abnormalities }\end{array}$ & $\begin{array}{c}\text { Rate of } \\
\text { chromosomal } \\
\text { abnormalities }(\%)\end{array}$ \\
\hline $\begin{array}{l}\text { Single ultrasound abnormalities } \\
\text { (Each abnormality occurs once: } a, b, c, d \text { ) }\end{array}$ & 57 & 2 & 3.51 \\
\hline $\begin{array}{l}\text { Multiple ultrasound abnormalities } \\
\text { (Each abnormality occurs twice or more: a, b, c, d) }\end{array}$ & 40 & 7 & 17.5 \\
\hline Cardiac structural abnormalities + other abnormalities & 25 & 4 & $16 \%$ \\
\hline Cleft lip and palate + other abnormalities & 3 & 1 & $33 \%$ \\
\hline Neck lymph cyst + hydramniosa $(\mathrm{a})+$ other abnormalities & 2 & 1 & $50 \%$ \\
\hline $\begin{array}{l}\text { Lateral ventricle broad (b) or posterior fossa pool broad } \\
\text { (c) or separation of the renal pelvis }(d)+\text { other anomalies }\end{array}$ & 10 & 1 & $20 \%$ \\
\hline Total & 97 & 9 & 9.28 \\
\hline
\end{tabular}

a, amniotic fluid index $>20 \mathrm{~cm}$; b, inner diameter of postcornu $>10 \mathrm{~mm}$; c, posterior fossa pool broad $>10 \mathrm{~mm}$; d, the renal pelvis separation 18-32 weeks' pregnancy $>4 \mathrm{~mm}$.

45,X (Turner syndrome)]. Among the 59 cases with normal gestation and birth, there were two chromosomal abnormalities $(3.39 \%)$; one trisomy 18 and one trisomy 21 . The rate of fetal chromosomal abnormalities was higher in women with a history of abnormal gestation and parturition than those with a normal history $(\mathrm{P}<0.01)$. The fetal chromosomal abnormality rates between pregnant women with a single abnormal indicator on the ultrasound and those with multiple indicators are compared in Table $\mathrm{V}$ and Fig. 7C. The rate of fetal chromosomal abnormalities was higher in cases where multiple abnormalities were observed on the ultrasound compared with cases where a single abnormality was observed on the ultrasound $(\mathrm{P}<0.05)$.

\section{Discussion}

Second trimester antenatal examination is a popular method to screen for chromosomal diseases. The examination is generally divided into two forms: Invasive prenatal examination, including amniotic cavity puncture and umbilical cord blood tube centesis, with confirmation of by chromosomal disease by chromosome karyotype analysis; and non-invasive examination, including peripheral blood fetal cell enrichment, serologic screening and ultrasound screening $(6,10,18)$. Because the invasive prenatal examination method can increase the high risk of miscarriage, intrauterine infection, fetal malformation and fetal intrauterine death, while enrichment of peripheral blood fetal cells is complex and expensive. Therefore, these methods are not suitable for screening of large populations. As ultrasound examination combined with serologic screening is simple, non-invasive, economical and reproducible, it is becoming more and more appealing option $(19,20)$.

Ultrasound screening for pregnant women with a single abnormal serum marker makes up for the limitations of the serological screening. The current study confirmed there is a risk of fetal chromosomal abnormalities among pregnant women with a single abnormal serum marker, and that ultrasound is useful for detecting indicators of chromosomal abnormalities.

The present study demonstrated that trisomy 18, trisomy 13, trisomy 21 and Turner syndrome non-integral chromosomal abnormalities was commonly, which is similar to a previous report (21). In the current study, among 7 cases with cardiac structural abnormalities accompanying other abnormalities observed on the ultrasound, 4 (57\%) had chromosomal abnormalities, which was also in accordance with the previous report (22). Cleft lip and palate combined with other deformities are strong indicators of chromosomal abnormalities. In the present study, 1 out of 2 cases of cleft lip with other malformations was confirmed as trisomy 13 syndrome. A lymphatic hygroma on the neck is a typical indicator of the deadly Turner syndrome, which is a common sex chromosome abnormality that occurs in $0.27 \%$ of female newborns (23); cystic lymphangioma and edema in the extremities are the main indictors of Turner syndrome in prenatal ultrasound screening. In the current study, the 2 cases with fetal neck lymphatic hygroma and the case with Turner syndrome chose to terminate the pregnancy. The optimal time to undergo prenatal ultrasound screening is at $18-24$ weeks. The present study confirmed that other fetal chromosomal abnormalities, in addition to trisomy 21 , also existed in those with a single abnormal serum marker, which is in accordance with a previous report (24). However, whatever screening method is used only assesses the risk of fetal chromosome abnormalities, which is a disadvantage of ultrasound screening (19), thus, for diagnosis, karyotype analysis is indispensable.

Additionally, age is also a risk factor for pregnancy with chromosome abnormalities (Table II), as has been reported previously $(25,26)$. Pregnant women older than 35 years carry a high risk of Down's syndrome. In this study, of the 9 abnormal fetuses, all chose termination of the pregnancy. This study also confirmed that pregnant women with abnormal gestation and birth history had a high risk of fetal chromosome aberration (Table IV), which may be 


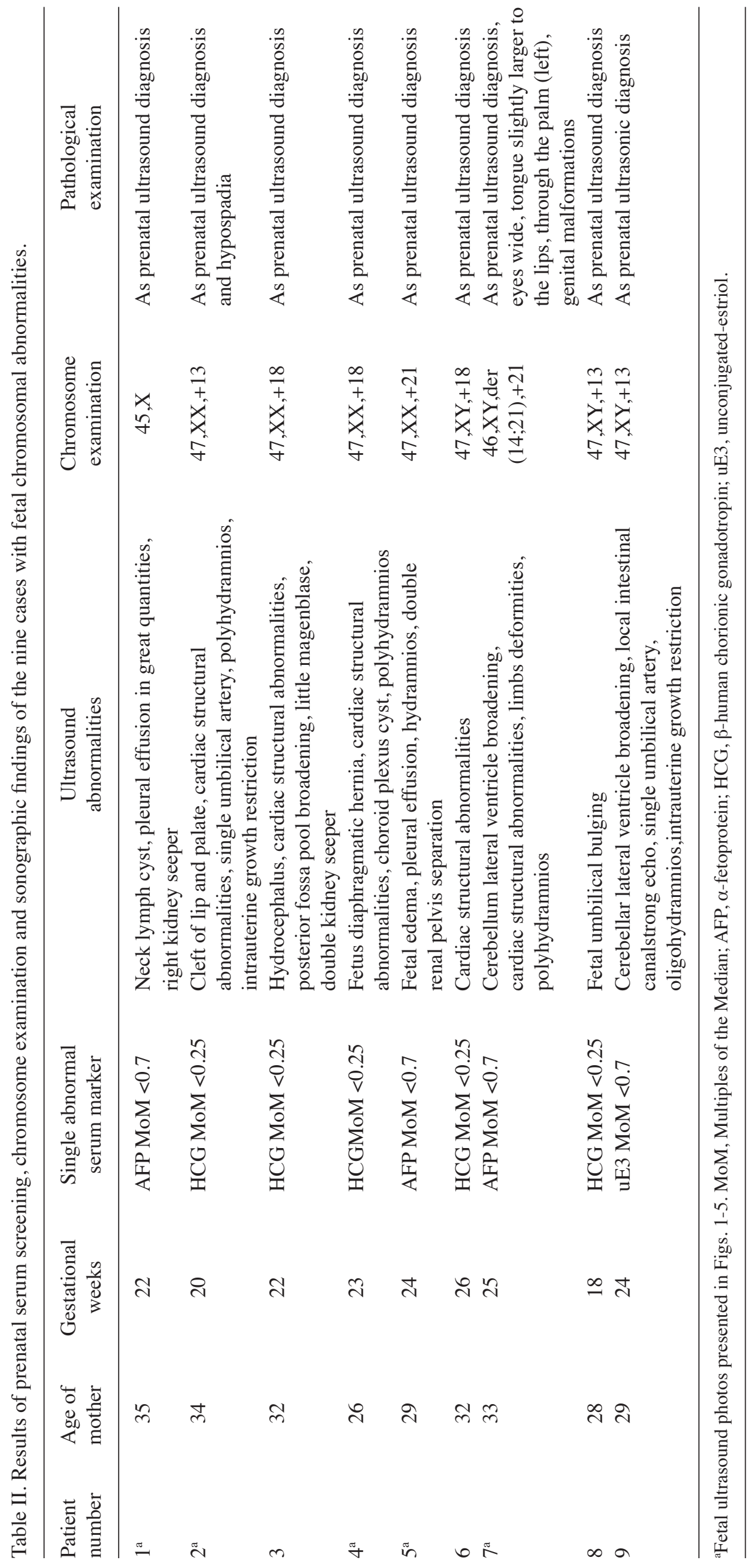



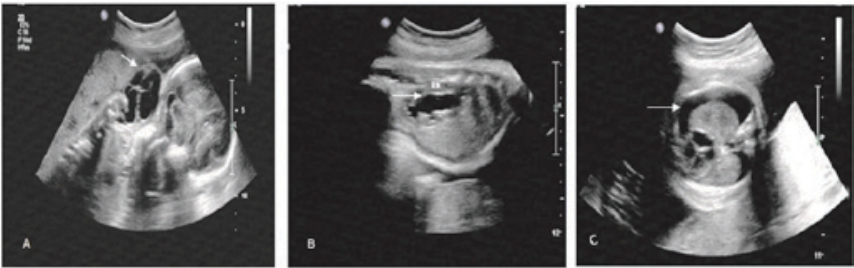

Figure 1. Ultrasound observation at 22 weeks. Single maternal serologic screening index $\alpha$-fetoprotein MoM $<0.7$. Ultrasound revealed fetal neck lymphatic hygroma, high hydrothorax and right kidney see per. Amniotic fluid analysis confirmed the chromosome number as $45, \mathrm{X}$ (case 1) (A) Prenatal ultrasound revealed fetal neck lymphatic hygroma, in which there were multiple rooms can be seen; (B) fetal right kidney see per; (C) high hydrothorax.
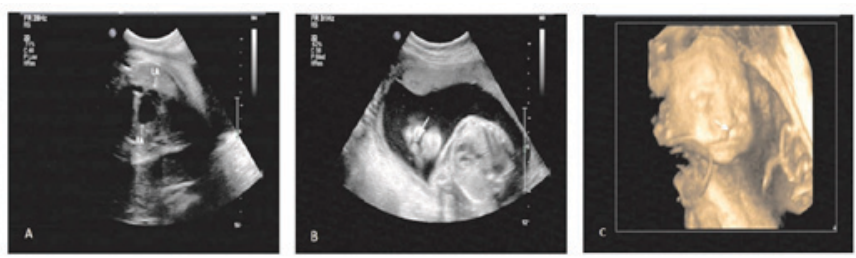

Figure 2. Ultrasound observation at 20 weeks. The single maternal serologic screening index of this case was $\beta$-human chorionic gonadotropin MoM $<0.25$. Ultrasound revealed cleft lip and palate, cardiac structural abnormalities, amniotic fluid chromosome analysis were confirmed as 47,XX, chromosome 13 trisomy (case 2). (A) Prenatal ultrasound revealed cardiac structural abnormalities, RA is larger than LA. (B) Prenatal two-dimensional ultrasound fetal revealed cleft lip. (C) Prenatal three-dimensional ultrasound revealed fetal cleft lip. RA, right atrium; LA, left atrium.
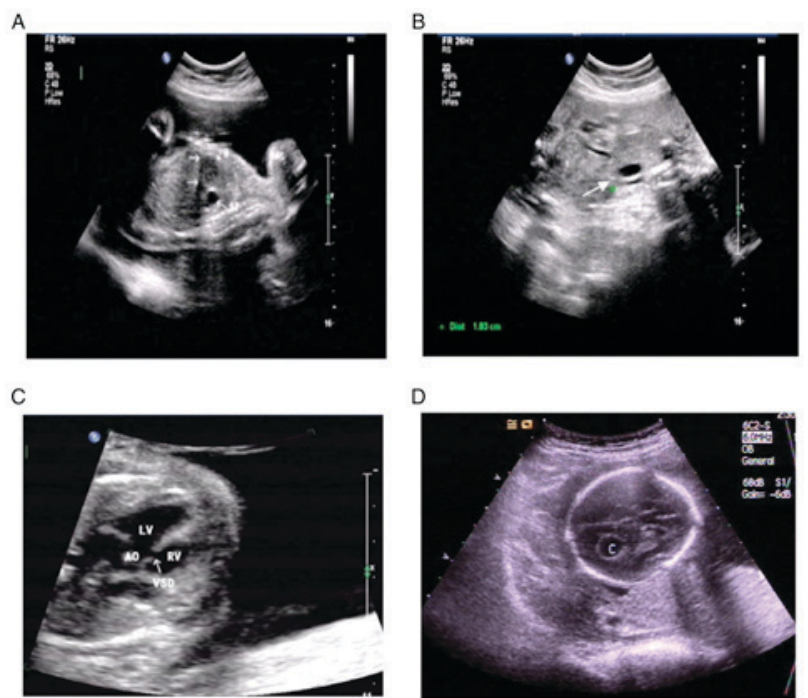

Figure 3. Ultrasound observation at 23 weeks. Single maternal serologic screening index revealed was $\beta$-human chorionic gonadotropin $\mathrm{MoM}<0.25$, ultrasound revealed fetal diaphragmatic hernia, heart ventricular septal defect, choroid plexus cyst, amniotic fluid chromosomes were confirmed as $47, \mathrm{XX},+18$ trisomy part (case 4). (A) Prenatal ultrasound revealed fetal diaphragmatic hernia, ST and $\mathrm{H}$ simultaneously located in the chest cavity. (B) Prenatal ultrasound revealed fetal diaphragmatic hernia ring. (C) Prenatal ultrasound revealed fetal cardiac ventricular septal defect. (D) prenatal ultrasound revealed a fetal choroid plexus cyst. ST, magenblase; $\mathrm{H}$, heart; AO aorta; RV, right ventricle; $L V$, left ventricle; VSD, ventricular septal defect.

closely associated with any chromosome abnormality of the couple (27). Therefore, chromosome analysis of the parents
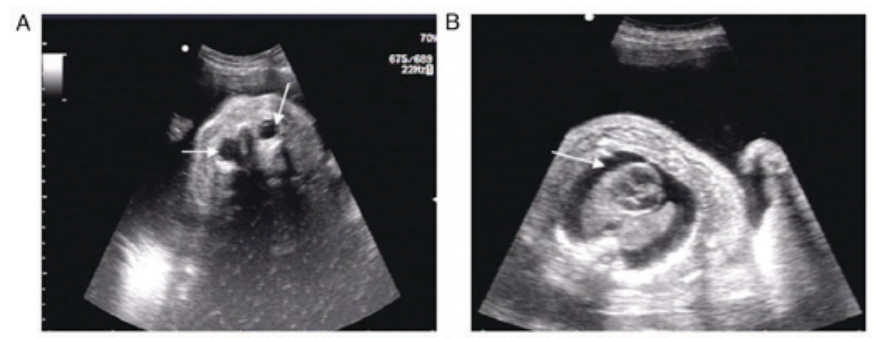

Figure 4. Ultrasound observation at 24 weeks. Single maternal serologic screening index $\alpha$-fetoprotein MoM <0.7. Ultrasound revealed fetal hyposarca and hydrothorax. Umbilical cord blood chromosome analysis confirmed $47, \mathrm{XX},+21$ trisomy (case 5) (A) Prenatal ultrasound revealed fetal facial edema, arrow indicated eyes. (B) Prenatal ultrasound revealed hydrothorax.
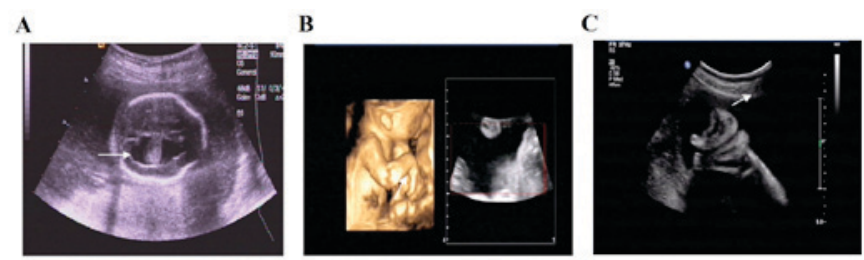

Figure 5. Ultrasound observation at 25 weeks. Single maternal serologic screening index $\alpha$-fetoprotein MoM $<0.7$. Ultrasound revealed fetal lateral ventricle broadening, limb deformities. Umbilical cord blood chromosome analysis confirmed 46,XY, der (14,21),+21 trisomy (case 5) (A) Prenatal ultrasound revealed fetal lateral ventricle broadening. (B) Antenatal fetal three-dimensional ultrasonography revealed a deformity of the right wrist. (C) Prenatal ultrasound revealed deformity of a toe on the right foot.
A

$$
\begin{aligned}
& \text { I) } 18 \text { 18 } \\
& \text { 6) } 40 \text { B } \\
& \frac{8 \pi x}{4}=3
\end{aligned}
$$

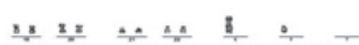

$$
\begin{aligned}
& \text { C }
\end{aligned}
$$$$
\text { C }
$$

$\mathrm{E}$

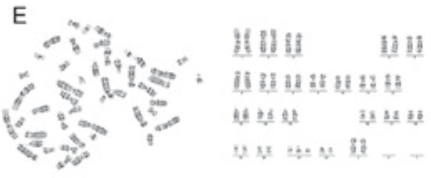

B

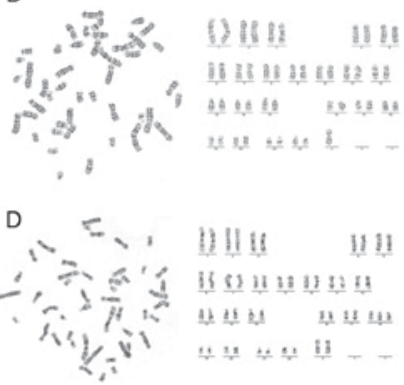

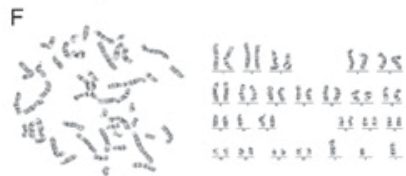

Figure 6. Karyotype analysis. (A) Karyotype analysis of normal karyotype: 46,XY. (B) Karyotype analysis of Turner syndrome: 45,X (C) Karyotype analysis of trisomy 13: 47,XX, +13. (D) Karyotype analysis of trisomy 18: $47, X X,+18$. (E) Karyotype analysis of trisomy 21: 47,XX,+21. (F) Karyotype analysis of trisomy 21 : 46, XX, der (14,21), +21 (x400 magnification).

may be important for those with abnormal gestation and birth histories. Additionally, the chromosome abnormality rate of with multiple abnormal features observed on the ultrasound as higher than when a single abnormal feature was observed on the ultrasound, which is consistent with the report by Nicolaides (28). The results of the present study indicate that ultrasound screening combined with serological screening is an effective method for identifying a risk of fetal chromosomal abnormalities. 
Table III. Comparison of fetal chromosomal abnormalities rate between those with abnormal ultrasound indicators and the control group.

\begin{tabular}{lcccc}
\hline Group & $\begin{array}{c}\text { Abnormal } \\
\text { karyotype }\end{array}$ & $\begin{array}{c}\text { Normal } \\
\text { karyotype }\end{array}$ & Total & $\begin{array}{c}\text { Abnormality } \\
\text { rate }(\%)\end{array}$ \\
\hline Control & 0 & 92 & 92 & 0 \\
Observed & 9 & 88 & 97 & $9.28^{\mathrm{a}}$ \\
Total & 9 & 180 & 189 & 4.76 \\
\hline
\end{tabular}

${ }^{\mathrm{a}} \mathrm{P}<0.01$ vs. control.

Table IV. Comparison of the fetal chromosomal abnormalities rate of the 97 pregnant women (those with abnormalities on ultrasound) with different gestation and parturition history.

\begin{tabular}{lcccc}
\hline Group & $\begin{array}{c}\text { Abnormal } \\
\text { karyotype }\end{array}$ & $\begin{array}{c}\text { Normal } \\
\text { karyotype }\end{array}$ & Total & $\begin{array}{c}\text { Abnormality } \\
\text { rate }(\%)\end{array}$ \\
\hline No AGPH & 2 & 57 & 59 & 3.39 \\
AGPH & 7 & 31 & 38 & $18.42^{\mathrm{a}}$ \\
Total & 9 & 88 & 97 & 9.28 \\
\hline
\end{tabular}

AGPH, abnormal gestation and parturition history; ${ }^{\text {a }}<0.05$ vs. no AGPH.

Table V. Comparison of fetal chromosomal abnormalities rate between single and multiple abnormal ultrasound indicators (AUI).

\begin{tabular}{lcccc}
\hline AUI & $\begin{array}{c}\text { Abnormal } \\
\text { karyotype }\end{array}$ & $\begin{array}{c}\text { Normal } \\
\text { karyotype }\end{array}$ & Total & $\begin{array}{c}\text { Abnormality } \\
\text { rate }(\%)\end{array}$ \\
\hline $\begin{array}{l}\text { Single } \\
\text { abnormality } \\
\begin{array}{l}\text { Multiple } \\
\text { abnormalities }\end{array}\end{array}$ & 2 & 55 & 57 & 3.51 \\
Total & 9 & 33 & 40 & $17.5^{\mathrm{a}}$ \\
\hline
\end{tabular}

${ }^{\mathrm{a}} \mathrm{P}<0.05$ vs. single abnormality.

A deficiency of the current study is that not $100 \%$ of chromosome abnormalities produce features that can be screened for using ultrasound. In the control group, with an abnormal serum marker and no abnormalities observed on the ultrasound, no chromosomal abnormalities were identified by karyotype analysis; but considering the sample size is small, the relationship cannot be confirmed confidently, thus the further studies sound include a greater number of patients.

In conclusion, ultrasound examination can be effectively used to assist in screening for fetal chromosome abnormalities in pregnant women that have a risk of Down's syndrome risk
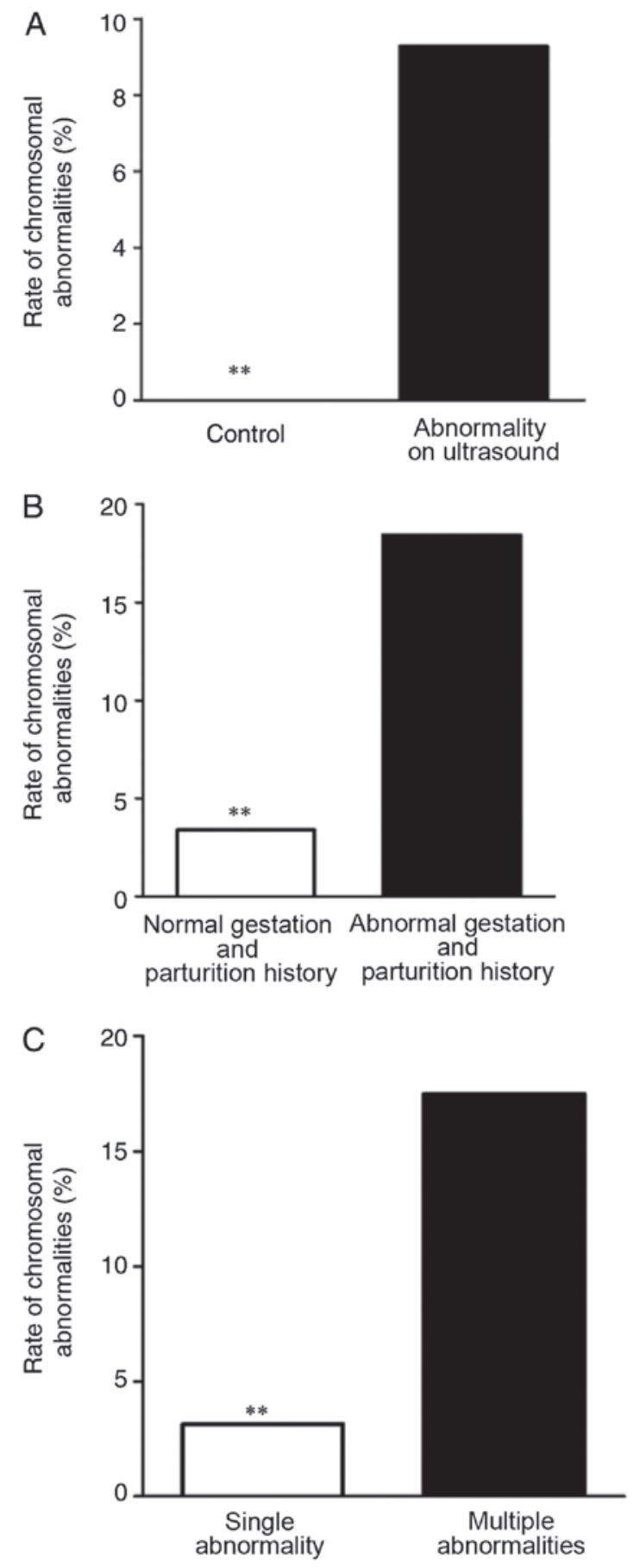

Figure 7. Comparison of the chromosomal abnormality rate. (A) Pregnant women with and without abnormalities observed on theultrasound; (B) Pregnant women with and without abnormal gestation and birth history; (C) Single and multiple abnormalities observed by ultrasound. ${ }^{* *} \mathrm{P}<0.01$.

rate $>1 / 270$ and trisomy 18 risk rate $>1 / 350$ (serologic trigeminy screening) and a single abnormal serum marker. These pregnant women have a high risk of fetal chromosomal abnormalities.

\section{References}

1. Benn P: Expanding non-invasive prenatal testing beyond chromosomes 21, 18, 13, X and Y. Clin Genet 90: 477-485, 2016.

2. Gardner RJM and Sutherland GR: Chromosome abnormalities and genetic counseling. 3rd edition. Oxford University Press, Oxford, 2004. 
3. Nielsen $\mathrm{J}$ and Wohlert M: Chromosome abnormalities found among 34,910 newborn children: Results from a 13-year incidence study in Arhus, Denmark. Hum Genet 87: 81-83, 1991.

4. Abramsky L, Hall S, Levitan J and Marteau TM: What parents are told after prenatal diagnosis of a sex chromosome abnormality: Interview and questionnaire study. BMJ 322: 463-466, 2001.

5. Roizen NJ and Patterson D: Down's syndrome. Lancet 361: 1281-1289, 2003.

6. Alfirevic Z and Neilson JP: Antenatal screening for Down's syndrome. BMJ 329: 811-812, 2004

7. Botto LD, May K, Fernhoff PM, Correa A, Coleman K, Rasmussen SA, Merritt RK, O'Leary LA, Wong LY, Elixson EM, et al: A population-based study of the 22q11.2 deletion: Phenotype, incidence, and contribution to major birth defects in the population. Pediatrics 112: 101-107, 2003.

8. Miao ZY, Liu X, Shi TK, Xu Y, Song QH and Tang SH: First trimester, second trimester, and integrated screening for Down's syndrome in China. J Med Screen 19: 68-71, 2012.

9. Hansen M, Kurinczuk JJ, Bower C and Webb S: The risk of major birth defects after intracytoplasmic sperm injection and in vitro fertilization. N Engl J Med 346: 725-730, 2002.

10. Mademont-Soler I, Morales C, Soler A, Martínez-Crespo JM, Shen Y, Margarit E, Clusellas N, Obón M, Wu BL and Sánchez A Prenatal diagnosis of chromosomal abnormalities in fetuses with abnormal cardiac ultrasound findings: Evaluation of chromosomal microarray-based analysis. Ultrasound Obstet Gynecol 41: 375-382, 2013.

11. Alfirevic Z, Sundberg K and Brigham S: Amniocentesis and chorionic villus sampling for prenatal diagnosis. Cochrane Database Syst Rev: CD00325, 2003.

12. Pallister PD, Pallister AB, South S, Toydemir R, Johnson JP, Beischel L and Opitz JM: A deletion 13q34/duplication $14 \mathrm{q} 32.2-14 \mathrm{q} 32.33$ syndrome diagnosed 50 years after neonatal presentation as infantile hypercalcemia. Am J Med Genet A 155A: 833-839, 2011.

13. Harrison MR, Keller RL, Hawgood SB, Kitterman JA, Sandberg PL, Farmer DL, Lee H, Filly RA, Farrell JA and Albanese CT: A randomized trial of fetal endoscopic tracheal occlusion for severe fetal congenital diaphragmatic hernia. N Engl J Med 349: 1916-1924, 2003.

14. Socié G, Gluckman E, Carosella E, Brossard Y, Lafon C and Brison O: Search for maternal cells in human umbilical cord blood by polymerase chain reaction amplification of two minisatellite sequences. Blood 83: 340-344, 1994.

15. Hromadníková I, Sedlácková L, Mrstinová M, Stechová K, Karamanov S, Kofer J and Macek M: Levels of peripheral circulating nucleated erythrocytes in pregnant women for noninvasive prenatal diagnosis. Ceska Gynekol 65: 33-37, 2000 (In Czech).
16. Oneda B, Steindl K, Masood R, Reshetnikova I, Krejci P, Baldinger R, Reissmann R, Taralczak M, Guetg A, Wisser J, et al: Noninvasive prenatal testing: More caution in counseling is needed in high risk pregnancies with ultrasound abnormalities. Eur J Obstet Gynecol Reprod Biol 200: 72-75, 2016.

17. Frank M, Maymon R, Wiener Y, Neeman O, Kurzweil Y and Bar J: The effect of hereditary versus acquired thrombophilia on triple test Down's syndrome screening. Prenat Diagn 33: 191-195, 2013.

18. Hui WW and Chiu RW: Noninvasive prenatal testing beyond genomic analysis: What the future holds. Curr Opin Obstet Gynecol 28: 105-110, 2016.

19. Baillie C, Smith J, Hewison J and Mason G: Ultrasound screening for chromosomal abnormality: Women's reactions to false positive results. Br J Health Psychol 5: 377-394, 2000.

20. Shipp TD and Benacerraf BR: Second trimester ultrasound screening for chromosomal abnormalities. Prenat Diagn 22: 296-307, 2002

21. Nyberg DA and Souter VL: Sonographic markers of fetal trisomies: Second trimester. J Ultrasound Med 20: 655-674, 2001

22. Moran CJ, Tay JB and Morrison JJ: Ultrasound detection and perinatal outcome of fetal trisomies 21,18 and 13 in the absence of a routine fetal anomaly scan or biochemical screening. Ultrasound Obstet Gynecol 2 20: 482-485, 2002.

23. Bondy CA; Turner Syndrome Study Group: Care of girls and women with Turner syndrome: A guideline of the Turner syndrome study group. J Clin Endocrinol Metab 92: 10-25, 2007.

24. Massé J, Summers A, Cherian G and Forest J: Transportation of maternal serum specimens for screening for chromosomal aneuploidies: Effect of seasonal variations, distance, and freezing on the stability of the biological markers. Clin Biochem 33: 273-277, 2000.

25. Sancken U and Bahner D: Comparison of triple-risk assessment of fetal trisomy 21 including total human choriogonadotropin (hCG) or its free $\beta$-subunit (free $\beta$ hCG). Fetal Diag Ther 18: 122-127, 2003

26. Goetzl L, Krantz D, Simpson JL, Silver RK, Zachary M, Pergament E, Platt LD, Mahoney MJ and Wapner RJ: Pregnancy-associated plasma protein A, free beta-hCG, nuchal translucency, and risk of pregnancy loss. Obstet Gynecol 104: 30-36, 2004.

27. Cheung MC, Goldberg JD and Kan YW: Prenatal diagnosis of sickle cell anaemia and thalassaemia by analysis of fetal cells in maternal blood. Nat Genet 14: 264-268, 1996

28. Nicolaides K: Screening for chromosomal defects. Ultrasound Obstet Gynecol 21: 313-321, 2003. 